\title{
Terapi kognitif pada permasalahan hubungan sosial
}

$\Psi$ PROCEDIA Studi Kasus dan Intervensi Psikologi p-ISSN 2302-1462; e-ISSN 2722-7669 ejournal.umm.ac.id/index.php/procedia 2021, Vol 9(4):134-137

DOI:10.22219/procedia.v9i4.16336

(C) The Author(s) 2021

(ㅇ)(ㅇ) 4.0 International license

\author{
Lintang Aulia Utami ${ }^{1}$
}

\begin{abstract}
One of the tasks of child development is to establish and build social relationships with friends and their environment. Individuals who have been socially excluded will withdraw by not having relationships with others because of the fear of the negative evaluation feom others. The assessment methods used were interview, observation and psychological tests namely were graphic tests, and the Intelligenz Structure Test (IST). The intervention used to change the subject's negative thoughts to become more positive is cognitive therapy. The cognitive therapy process that was given as many as 6 sessions with the target subject was able to change his negative thoughts into more positive ones. The results of the intervention show that the subject was able to replaces his negative thoughts with positive thoughts which ultimately makes the subject feel no guilt anymore.
\end{abstract}

\section{Keywords}

Cognitive distortion, cognitive therapy, social relations

\section{Pendahuluan}

Salah satu tugas dalam perkembangan anak ialah menjalin dan membangun hubungan sosial dengan sebayanya dan lingkungannya. Anak-anak memiliki minat dan aktifitas yang dapat terbentuk dengan baik ketika bermain bersama teman-temannya, memiliki keinginan yang cukup kuat untuk dapat diterima oleh kelompoknya. Namun, tidak semua anak-anak dapat membangun hubungan sosial yang baik sehingga tidak sedikit dari mereka dapat diterima dalam kelompok. Anak yang ditolak atau terkucilkan dari kelompoknya akan mengalami dampak "psikologis" dan mempengaruhi penyesuaian sosialnya yang akhirnya akan berpengaruh pada penyesuaian diri dan perkembangan pribadi anak. Hal ini dapat memberikan pengaruh pada masa depan anak saat tumbuh dewasa yang akan membentuk sikap-sikap yang maladaptive seperti menarik diri, tidak mampu menyesuaikan diri dengan lingkungan, depresi, dan kecemasan (Santrock, 2011).

Dikucilkan secara sosial memiliki dampak negatif pada ketidakstabilan emosi, bias dalam memproses informasi (proses kognitif), adanya indikasi agresif, kesepian dan depresi. Individu yang dikucilkan secara sosial akan menarik diri dengan tidak menjalin hubungan dengan orang lain dikarenakan adanya ketakutan akan penilaian dan evaluasi negatif yang dulu pernah dialami akan terulang kembali (Syrjämäki, 2019).

Hal ini terjadi pada subjek yang memiliki pengalaman masa kecil dikucilkan dengan cara diejek oleh teman sekelasnya yang membuat subjek menarik diri dan mengalami hambatan pada penyesuaian diri dan lingkungan sosialnya.
Peristiwa tersebut mengembangkan pemikiran buruk subjek terhadap orang lain atas dirinya, dan membuat subjek merasa sedih, merasa bersalah dan menangis. Intervensi yang digunakan untuk mengubah pemikiran negatif subjek menjadi lebih kontruktif adalah terapi kognitif.

\section{Metode Asesmen}

Metode asesmen yang digunakan adalah wawancara klinis, observasi dan pemberian tes psikologi berupa Tes Grafis, dan Intelligenz Structure Test (IST). Wawancara klinis, yaitu wawancara yang dilakukan guna mengumpulkan informasi secara mendalam baik melalui subjek maupun orang-orang di sekitar subjek, misalnya kedua orang tua, paman, dan perawat ruangan subjek. Wawancara klinis dilakukan untuk mengetahui simtom-simtom gangguan subjek dan perilaku yang akan diintervensi dengan mengacu pada pedoman wawancara yang disusun berdasarkan Diagnostic and Statistical Manual of Mental Disorder Fifth Edition (DSM-V).

Observasi yang dilakukan dengan tujuan untuk mengetahui tingkat keberfungsian dan perilaku subjek saat ini. Checklist observasi yang digunakan adalah World Health

\footnotetext{
${ }^{1}$ Pusat Layanan Disabilitas dan Inklusi, Kalimantan Selatan
}

\section{Korespondensi:}

Lintang Aulia Utami, Pusat Layanan Disabilitas dan Inklusi Kalimantan Selatan, Komplek Bumi Indah Lestari II, JI. Perdagangan, Kuin Utara, Banjarmasin Utara, Kota Banjarmasin, Kalimantan Selatan 70124 Email: Lintangauliautami@gmail.com 
Organization Dissability Assessment (WHODAS). Tes Grafis digunakan untuk mengungkap kepribadian dan konsep diri subjek secara mendalam. Tes Grafis yang diberikan ialah Draw a Person (DAP), BAUM, dan House Tree Person (HTP). Intelligenz Structure Test (IST) diberikan guna mengetahui bagaimana kapasitas intelektual subjek untuk memastikan kecocokan pemberian intervensi pada subjek.

\section{Presentasi Kasus}

Subjek merupakan seorang mahasiswi berusia 20 tahun. Sejak kecil subjek dibesarkan oleh neneknya. Orang tua subjek bekerja menjadi Tenaga Kerja Indonesia (TKI) di luar negeri. Subjek mengaku tidak dekat dengan orangtuanya, orangtua subjek hanya beberapa kali dalam sebulan menelepon untuk menanyakan kabar subjek. Saat di bangku SD subjek pernah diejek oleh teman sekelasnya tentang orangtuanya yang tidak pernah mengambil rapor. Subjek diejek anak yang dibuang oleh teman sekelasnya. Subjek menangis dan memberi tahu nenek dan orangtuanya, namun respon orangtua dan neneknya hanya meminta subjek tetap sabar dan tidak boleh dendam. Sejak saat itu, subjek mengaku selalu memiliki pemikiran negatif terhadap orang lain atas dirinya. Subjek mengaku sering merasa cemas atas pikirannya sendiri sehingga tidak jarang subjek memilih untuk menghindari orang lain dikarenakan pemikiran negatif subjek terhadap orang tersebut.

Berdasarkan dari hasil Tes Grafis, subjek menggambar anak perempuan berusia tujuh tahun. Ketika usia tujuh tahun itulah subjek pertama kali diejek oleh teman sekelasnya dan subjek merasa dikucilkan di sekolahnya. Subjek merupakan pribadi yang introvert dan sangat sensitif terhadap lingkungan sekitar. Subjek juga diidentifikasikan sebagai individu yang masih berorientasi pada masa lalu, memiliki penilaian atau pemikiran yang primitif dan kekanak-kanakan. Subjek cenderung tidak mampu mengontrol dorongannya sehingga menjadikan subjek kurang rasional dalam bertindak. Subjek juga memiliki kecenderungan paranoid yang sesuai dengan pernyataan subjek mengenai bagaimana cara subjek memandang orang lain yang selalu penuh curiga dan negatif. Subjek memiliki skor IQ 101 dengan kategori rata-rata. Subjek memiliki daya tangkap dan pemahaman yang baik serta memiliki cara berpikir yang teoritis dan kaku.

Subjek mengaku bahwa sering memiliki prasangka buruk pada orang lain. Subjek memikirkan bahwa orang lain akan menceritakan keburukan dan mengejek subjek. Hal ini membuat subjek merasa cemas dan takut untuk melakukan kegiatan dengan orang tersebut. Saat ini subjek memiliki sahabat lawan jenis namun subjek selalu merasa takut berlebihan ketika subjek ingin menghubungi atau menghabiskan waktu bersama dengan sahabatnya. Subjek memprediksi pikiran orang lain bahwa orang-orang akan mengejek jalinan pertemanan mereka. Subjek juga tidak jarang membatalkan atau menjauhi sahabatnya tanpa alasan yang jelas yang tidak bisa subjek sampaikan pada sahabatnya. Subjek merasa malu dan takut sahabatnya akan meninggalkannya apabila mereka diejek, akhirnya subjek memilih untuk menjauh sebelum subjek dijauhi lebih dulu. Namun, pemikiran tersebut tidak pernah terbukti kebenarannya yang akhirnya membuat subjek merasa bersalah terhadap pemikiran negatifnya kepada sahabatnya ataupun orang lain.

Subjek mengaku sering kali memprediksi pikiran orang lain atas dirinya dan menjauh dari lingkungannya tanpa alasan. Subjek juga mengaku sering mengambil keputusan disaat dirinya merasa tersinggung oleh orang lain. Subjek memutuskan keluar dari organisasinya ketika merasa bahwa subjek menjadi bahan pembicaraan di grup whatsapp (WA). Subjek tidak mencari sebabnya namun langsung mengundurkan diri. Saat subjek dijelaskan oleh teman organisasinya, subjek merasa bersalah dan malu telah mengambil keputusan disaat subjek merasa emosional. Subjek juga merasa bahwa tidurnya tidak berkualitas dengan merasakan kesulitan tidur di malam hari saat sedang merasa cemas dan khawatir.

Subjek memiliki distorsi/pikiran negatif yang ditandai dengan adanya distorsi kognitif sesuai dengan pengkategorian Beck yakni inferensi arbiter yaitu menarik kesimpulan dengan bukti-bukti yang tidak relevan. Subjek yang mengetahui dirinya tidak termasuk dalam obrolan grup kepanitian menyimpulkan bahwa subjek tidak dianggap dalam kepanitiaan sehingga subjek melakukan emotional reasonin dengan memutuskan sesuatu berlandaskan dengan emosi dan pikiran negatifnya. Hal ini membuat subjek memutuskan untuk keluar dari kepanitiaan berlandasan kesimpulan yang dibuat oleh subjek sendiri. Selain itu, subjek juga melakukan mind reading yakni memprediksi pikiran orang lain atas dirinya sendiri. Subjek ingin menghubungi temannya namun memprediksi terlebih dahulu apa yang akan orang lain pikirkan terhadap perilakunya yang akan menghubungi temannya. Subjek memprediksi orang lain akan mengejek kedekatan hubungan mereka.

Pendekatan yang dapat digunakan dalam masalah subjek ialah pendekatan kognitif. Beck menjelaskan bahwa individu yang mengalami kecemasan memiliki pemikiran negatif yang mengakibatkan terjadinya berbagai emosi yang dirasakan. Pendekatan Beck berfokus pada membantu individu mengindentifikasi pemikiran negatifnya lalu mengkoreksi pemikiran yang telah terdistorsi seperti kecenderungan memprediksi pikiran orang lain dengan hal negatif atau memandang diri sendiri buruk dan tidak berdaya. Keyakinan-keyakinan yang dibangun apabila mengandung keyakinan yang negatif maka akan menghasilkan perilaku yang negatif. Berdasarkan permasalahan tersebut maka intervensi yang cocok untuk mengatasi permasalahan subjek ialah terapi kognitif. 


\section{Diagnosis dan Prognosis}

Berdasarkan hasil asesmen yang telah dilakukakan, subjek hampir memenuhi semua gejala dari Diagnostic and Statistical Manual of Mental Disorder Fifth Edition (DSMV). Subjek memiliki kriteria diagnostik Other Personal Risk Factor V15.89. Faktor risiko disini adalah distorsi kognitif subjek dalam hubungan sosialnya.

Prognosis yang ditegakkan berdasarkan dari permasalahan subjek saat ini adalah baik. Hal ini didukung dengan status pendidikan, adanya keinginan untuk berubah menjadi lebih baik, tingkat keberfungsian yang baik dan adanya kesadaran terkait permasalahan pada pemikiran negatif subjek terhadap orang lain.

\section{Intervensi}

Jenis intervensi yang diberikan pada kasus ini adalah terapi kognitif. Terapi kognitif bertujuan untuk membantu subjek mengindentifikasikan pemikiran yang salah atau negatif, membantu subjek dalam memecahkan permasalahannya, mengevaluasi dan menanggapi pikiran negatif individu tentang dirinya, orang lain atau lingkungan sekitar dan masa depannya (Freeman et al., 1989). Alasan penggunaan terapi kognitif dengan alasan kesesuaian terhadap permasalahan yang subjek hadapi. Subjek memiliki distorsi terkait keyakinannya pada hubungan sosial dengan orang lain yang membuat subjek merasakan kecemasan dan kekhawatiran berlebihan serta membuat subjek memilih untuk menjauh dari lingkungannya. Terapi kognitif diberikan kepada subjek untuk menghilangkan prasangka buruk yang memunculkan kecemasan pada subjek sehingga diharapkan subjek dapat mengganti pemikiran menjadi lebih baik (Corey, 2013).

Teknik restrukturisasi kognitif bertujuan untuk mengindentifikasi pemikiran negatif yang sering kali muncul dan mengajarkan pada subjek untuk mengganti pikiran yang lebih positif dan rasional (Corey, 2013). Restrukturisasi kognitif dilakukan dengan menentang distorsi-distorsi subjek dan mendorong serta mengajarkan pemikiran yang lebih positif. Proses intervensi akan dilakukan dalam enam sesi, yakni:

Sesi I: Raport dan self contracting. Pada sesi pertama yaitu membangun raport dan membantu subjek mengidentifikasi masalah kekhawatirannya. Selanjutnya subjek diajak membangun komitmen agar bersungguh-sungguh dalam menjalani proses terapi yang akan ditargetkan dan menjelaskan kepada subjek sesi-sesi yang akan dilakukan. Selain itu dan subjek menetapkan tujuan yang disepakati bersama untuk proses terapi. Subjek juga menyadari keuntungan dan kerugian apabila pemikiran negatifnya ditangani.

Sesi II: Identifikasi distorsi. Pada sesi kedua ini, subjek dibantu dalam mengindentifikasi pemikiran negatifnya. Subjek mengungapkan hal-hal yang sering kali membuat subjek khawatir yakni (1) subjek memprediksi apa yang orang lain pikirkan tanpa ada bukti yang mendukung pemikirannya, mind reading. (2) Subjek fokus pada apa yang ia rasakan ketika merasa tersinggung pada suatu hal yang belum tentu kebenarannya. Subjek cenderung membuat keputusan disaat subjek merasakan perasaan emosional (Emotional reasoning). (3) Inferensi arbiter yaitu menarik kesimpulan tanpa adanya bukti yang mendukung.

Sesi III: Restrukturisasi kognitif. Pada sesi ketiga, mengajarkan hubungan antara pikiran, perasaan dan perilaku subjek. Subjek diminta untuk memikirkan dampak apa saja yang subjek rasakan dan akan tanggung dari pemikiran negatifnya. Subjek menyadari bahwa apa yang subjek lakukan selama ini salah. Selanjutnya subjek diberi form restrukturisasi kognitif untuk menuliskan pemikiran negatif subjek sehari-hari selama 10 hari.

Sesi IV: Restrukturisasi kognitif. Pada sesi ini subjek memberikan kertas tugas form restrukturisasi kognitif yang menuliskan pemikiran negatifnya selama 10 hari. Subjek dibantu melatih pemikiran yang positif dan lebih rasional serta mendorong subjek untuk dapat mempertahankan pemikiran positifnya yang telah subjek tulis pada kertas restrukturisasi kognitif.

Sesi V: Evaluasi dan terminasi. Pada sesi lima mengevaluasi keseluruhan sesi yang telah dilakukan. Selanjutnya terapi diakhiri dan memberikan support agar subjek tetap berpikir positif. Evaluasi menunjukkan bahwa subjek dapat melakukan restrukturisasi kognitif dengan baik.

Sesi VI: Follow up. Follow up dilakukan sebulan setelah intervensi yaitu menanyakan tentang keadaan subjek setelah intervensi. Subjek mengaku langsung mengganti pikiran negatifnya ketika muncul dengan pikiran yang positif yang akhirnya membuat subjek tidak merasakan perasaan bersalah lagi.

\section{Hasil dan Pembahasan}

\section{Hasil}

Subjek memiliki banyak distorsi kognitif mengenai lingkungan sosialnya yang kemudian beberapa dari distorsinya subjek internalisasikan pada dirinya yang kemudian subjek mengurangi distorsinya yakni yang paling utama adalah prasangka buruk kepada orang lain. Subjek perlahan-lahan belajar untuk berprasangka baik pada orang lain sehingga subjek tidak akan menginternalisasi pada dirinya lagi. Subjek merasa tidak berarti, tidak berguna dan tidak memiliki kelebihan, sehingga subjek merasa tidak percaya diri ketika berinteraksi dengan orang lain dan akhirnya subjek mengetahui bahwa ia hanya belum menemukan bakatnya, subjek bertekad untuk mencobacoba hal yang tidak pernah subjek coba sebelumnya seperti memasak dan bermain panah. Subjek juga cenderung mengambil keputusan saat sedang dikuasai emosinya kemudian subjek meminta masukan dan saran kepada seniornya, dan teman-temannya sebelum subjek memutuskan sesuatu saat sedang dikuasai emosinya. 


\section{Pembahasan}

Pemberian intervensi terapi kognitif dengan pendekatan restrukturisasi kognitif berhasil membuat subjek merubah distorsi kognitifnya menjadi lebih konstruktif dan positif. Perubahan terlihat dari setiap sesi yang dijalankan oleh subjek, dan form restrukturisasi kognitif yang diberikan pada subjek memperlihatkan bahwa subjek sudah mulai mengubah kebiasaan prasangka buruknya dengan pemikiran yang lebih positif. Subjek menjadi lebih tenang dibandingkan ketika memiliki prasangka buruk yang menghasilkan subjek menjadi terkadang merasa gelisah, takut dan khawatir.

Jenis distorsi kognitif yang dimiliki subjek selama ini ialah mind reading, emotional reasoning, dan inferensi arbiter. Inferensi arbiter yakni menarik kesimpulan dengan bukti-bukti yang tidak relevan. Subjek yang mengetahui dirinya tidak termasuk dalam obrolan grup kepanitiaan menyimpulkan bahwa subjek tidak dianggap dalam kepanitiaan sehingga subjek melakukan emotional reasoning dengan memutuskan sesuatu berlandaskan dengan emosi dan pikiran negatifnya. Hal ini membuat subjek memutuskan untuk keluar dari kepanitiaan berlandasan kesimpulan yang dibuat oleh subjek sendiri. Selain itu, subjek juga melakukan mind reading yakni memprediksi pikiran orang lain atas dirinya sendiri ketika subjek ingin menghubungi temannya. Sering memprediksi terlebih dahulu apa yang akan orang lain pikirkan terhadap perilakunya. Subjek memprediksi orang lain akan mengejek kedekatan hubungan mereka.

Dalam terapi kognitif penting untuk menantang pemikiran negatif tetapi juga melihat isi dari pemikiran negatifnya itu sendiri untuk dapat melihat metakognisi seseorang dengan pemikiran negatif (Papageorgiou, 2004). Terapi kognitif sangat efektif dalam mengurangi proses pemikiran negatif yang berulang dengan memberikan kemampuan untuk melepaskan diri dari pemikiran negatif yang dapat merubah suasana hati seseorang (Segal et al., 2013). Subjek yang sudah menemukan dan mengidentifikasi pemikiran negatifnya membuat ia memiliki pengetahuan pemikiran apa yang harus diubah. Ketika individu belajar untuk mengevaluasi pemikiran yang dimiliki dengan cara yang realistis dan lebih adaptif maka akan terjadi peningkatan emosi dan perilaku yang baik.

\section{Simpulan}

Intervensi yang telah dilakukan menunjukkan hasil sesuai dengan target, yaitu subjek dapat mengubah distorsi kognitif. Hal ini dapat terlihat dari distorsi kognitif subjek yang semakin berkurang dan bisa mengembangkan pikiran yang lebih positif.

Subjek juga berusaha untuk mengkomunikasikan kepada organisasinya ketika subjek merasakan kejanggalan dan menghindari untuk langsung mengambil kesimpulan. Subjek melakukannya perlahan-lahan dan subjek juga banyak bertanya dan meminta arahan kepada senior sekamarnya untuk membantu subjek dalam mengingatkan untuk tidak berpikir negatif atau berprasangka buruk pada orang lain.

\section{Referensi}

American Psychiatric Association. (2013). Diagnostic and statistical manual of mental disorders fifth edition. Washington DC.

Corey, G. (2013). Theory and practice of counseling and psychotherapy. Belmont, Calif: Wadsworth.

Freeman, A., Simon, K. M., Beutler, L. E., \& Arkowitz, H. (Eds.). (1989). Comprehensive handbook of cognitive therapy. Plenum Press.

Papageorgiou, C., \& Wells, A. (Eds.). (2004). Depressive rumination: Nature, theory and treatment. John Wiley \& Sons.

Santrock, John W.. (2011). Educational Psychology (Edisi ke- 5). New York: McGraw-Hill.

Segal, Z. V., Williams, J. M. G., \& Teasdale, J. D. (2013). Mindfulness-Based Cognitive Therapy for Depression (2nd ed.). New York: The Guilford Press

Syrjämäki, A. H., \& Hietanen, J. K. (2019). The effects of social exclusion on processing of social information - A cognitive psychology perspective. The British journal of social psychology, 58(3), 730-748. https://doi.org/10.1111/ bjso. 12299 